CVIA

EDITORIAL

pISSN 2508-707X / eISSN 2508-7088 https://doi.org/10.22468/cvia.2019.00038 CVIA 2019;3(2):31-31
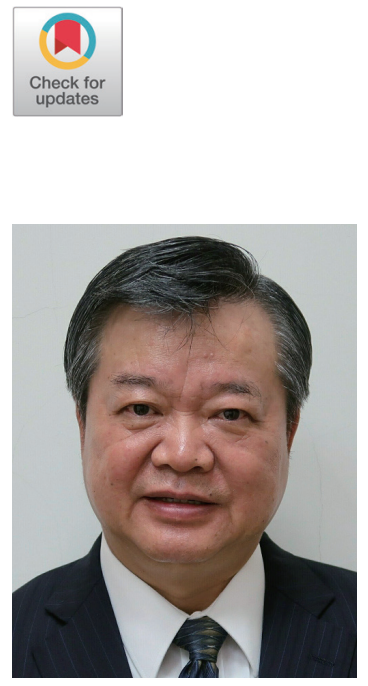

Received: April 9, 2019

Accepted: April 11, 2019

\section{Message from the New President of ASCI}

\author{
Yung-Liang Wan \\ President of Asian Society of Cardiovascular Imaging (ASCI) \\ Honorable Professor of Radiology, College of Medicine, Chang Gung University, Taoyuan, Taiwan \\ Consultant Radiologist Linkou Chang Gung Memorial Hospital, Taoyuan, Taiwan
}

\section{Dear Colleagues,}

The Asian Society of Cardiovascular Imaging (ASCI) is now 13 years old since its establishment in 2006. ASCI is dedicated to the advancement of cardiovascular imaging in Asia, the largest of the earth's continents containing more than $60 \%$ of the global population. It is my privilege and honor to become the 6th President of ASCI. In the past 12 years, the Society's continued development has been tremendously beneficial to radiologists, cardiologists, patients, physicians, scientists, and the entire healthcare profession altogether. It is my pleasure to take this opportunity to extend my appreciation to the former Presidents of ASCI, Professor Tae-Hwan Lim, Professor Sachio Kuribayashi, Dr. John Hoe, Professor Yeon Hyeon Choe and Professor Hajime Sakuma, for their illustrious contribution and achievements in the progression of this Society. I must also emphasize that in the past two years, Professor Sakuma has contributed a lot to our field, especially in strengthening the relationship and collaboration with our Sister Societies ESCR, EACVI, SCMR, NASCI, and SCCT. The 13th Annual Congress of ASCI was successfully held in Taipei, Taiwan from March 21st to 23rd, 2019. There were more than 400 attendees, including 89 invited speakers and guests from 17 countries; 52 invited lecturers and 171 submissions, including 112 scientific abstracts. As an Honorary President of ASCI 2019, I would like to thank the hardworking and intelligent Congress President of ASCI 2019, Professor Yeun-Chung Chang and Organizing Committee members. My appreciation also goes to all attendees, ASCI officers, EC members, invited speakers and guests, delegates from Sister Societies and industry sponsors for their participation and support. This new term, I have set up the International Advisory Committee by inviting a few respected pioneers. This is also to acknowledge that the ASCI school, established in 2018 and chaired by Professor Jongmin Lee, plays a critical role in educating and training our younger generation through the ASCI Cube, the Joint Symposium and the Speaker Bureau. Serving as President of ASCI for the 2019 to 2021 term, I plan to expand the ASCI family and continuously promote the role of ASCI in education, scientific work and professional service to patients through international collaboration with our Sister Societies. The official journal of ASCI, CVIA, has been one of our most important accomplishments and a true milestone of ASCI. Four years ago, the journal was successfully launched by Professor Tae-Hoon Kim, its first Editor-in-Chief, and it will continue to be fostered by the new Editor-in-Chief, Professor Sang-Il Choi. CVIA has been playing a crucial role in the diagnosis, optimal management and improvement of outcomes for patients with cardiovascular disease in Asia. It will be highly appreciated if radiologists, cardiologists and scientists working in the field of cardiovascular imaging could submit their original scientific works, review articles and papers on guidelines to CVIA. 